\title{
In vivo diagnosis and characterization of gastric Crohn's disease using endomicroscopy and virtual chromoendoscopy
}

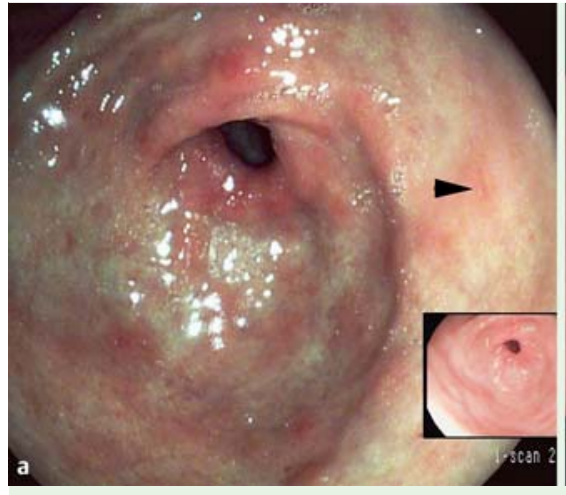

Fig. 1 Endoscopic appearances of the stomach in a 33-year-old man with a history of ileocolic Crohn's disease. a Virtual chromoendoscopy (i-Scan) revealing an erythematous and edematous inflamed mucosa in the gastric antrum, along with scattered typical Crohn's disease
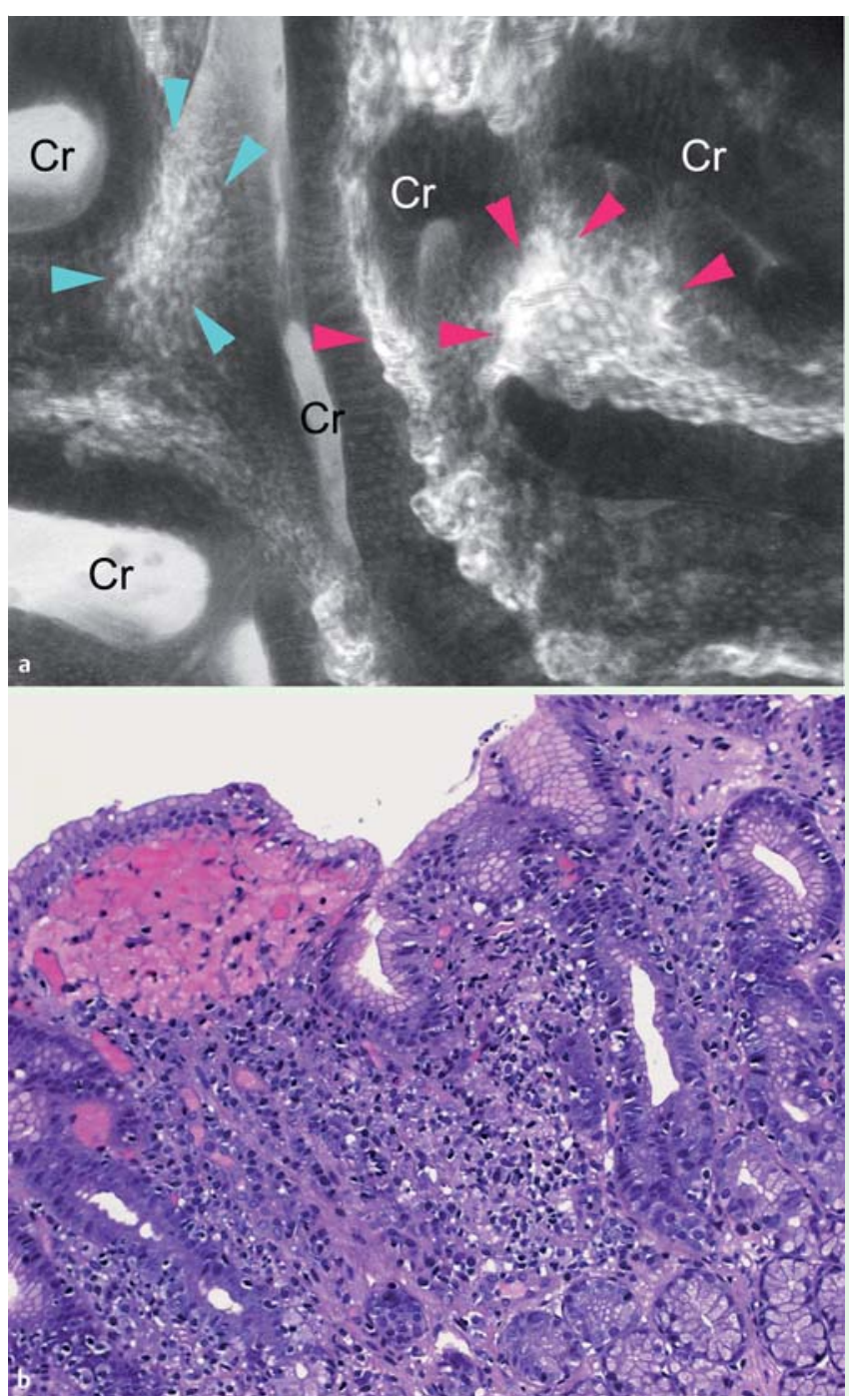

Confocal laser endomicroscopy (CLE) and virtual (dyeless) chromoendoscopy are sophisticated, so-called advanced imaging techniques within contemporary endoscopy. I-Scan (Pentax, Tokyo, Japan) is a computer-based color program that enhances the contrast of mucosal details, especially the superficial vascularization [1]. In contrast, CLE provides a deeper view, meaning that a real-time and in vivo visualization of a plethora of cellular and subcellular details can be achieved, which correlates with conventional histology $[2,3]$. Both techniques have an immense impact on modern endoscopic diagnosis and surveillance.

Several studies have described the utility of CLE for in vivo diagnosis of gastric disorders, such as Helicobacter gastritis [4], gastric intestinal metaplasia, and cancer [5]. However, no data are available regarding the utility of CLE and/or virtual chromoendoscopy for the in vivo description and diagnosis of gastric Crohn's disease. This brief article reports the first in vivo description and diagnosis of gastric Crohn's disease by two modern imaging techniques, i-Scan and CLE.

A 33-year-old man with a 1-year history of ileocolic Crohn's disease, currently being treated with topical budesonide therapy, was admitted to our department with progressively worsening nausea, vomiting, abdominal pain, and diarrhea over the preceding few weeks.

High definition white-light esophagogastroduodenoscopy (Pentax; EG-2990i) showed an edematous mucosa and scattered, typical aphthous lesions throughout the entire gastric mucosa ( $\bullet$ Fig. 1 ) and duodenal mucosa (not shown). After switching to the i-Scan mode, we were able to observe spots scattered throughout the erythematous mucosa especially in the gastric antrum ( $\bullet$ Fig. 1 a), which had not been evident in the white-light imaging (see insert in $\bullet$ Fig. 1 a).

The endoscopes were then changed to perform CLE (Pentax; EC-3870 CIK). After the intravenous administration of $5 \mathrm{~mL}$ of fluorescein (10\%; Alcon Pharma, Freiburg, Germany) as a contrast agent, we examined one of the spotted areas of the antral mucosa that had been highlighted by the i-Scan (marked between two biopsies). Endomicroscopy revealed an altered gastric epithelial architecture. In the mucosa of the lamina propria between the dilated and distorted gastric glands, we were able to identify leaking dilated vessels (fluorescein extravasation) and an inflammatory infiltrate ( Fig.2a). Subsequent histo- 
pathological evaluation of conventional biopsies taken from the same area using a hematoxylin and eosin (H\&E) stain confirmed the endomicroscopic inflammatory features ( Fig.2b). There was no evidence of Helicobacter pylori infection. In view of the obvious disease progression due to insufficient immunosuppression, the patient was commenced on systemic steroid therapy and azathioprine.

In summary, on the basis of these findings, we were able for the first time to describe the manifestations of gastric Crohn's disease and diagnose it in vivo, in a real-time and non-invasive manner, using i-Scan and fluorescein-guided CLE. The endomicroscopic findings were confirmed by conventional histopathology. Here, we highlight the clinical usefulness of these two advanced imaging techniques and the ability of virtual chromoendoscopy-guided CLE to diagnose gastric Crohn's disease in vivo. Future prospective blinded imaging studies are needed to quantify the accuracy, sensitivity and specificity of these two endoscopic approaches.
Endoscopy_UCTN_Code_CCL_1AB_2AD_3AC

Competing interests: None

\section{G. Hundorfean', A. Agaimy², A. Hartmann', M. T. Chiriac ${ }^{1,3}$, J. Siebler ${ }^{1}$, M. F. Neurath ${ }^{1}$, J. Mudter ${ }^{1}$}

${ }^{1}$ Medical Clinic I, University of ErlangenNuremberg, Erlangen, Germany

2 Institute of Pathology, University of Erlangen-Nuremberg, Erlangen, Germany

${ }^{3}$ Molecular Biology Center, Interdisciplinary Research Institute on Bio-Nano-Sciences and the Department of Biology, Babeş-Bolyai University, Cluj-Napoca, Romania

\section{References}

1 Kodashima S, Fujishiro M. Novel image-enhanced endoscopy with i-scan technology. World J Gastroenterol 2010; 16: 1043

2 Neumann $H$, Kiesslich $R$, Wallace MB et al. Confocal laser endomicroscopy: technical advances and clinical applications. Gastroenterology 2010; 139: 388-392

3 Inoue H, Kudo SE, Shiokawa A. Technology insight: Laser-scanning confocal microscopy and endocytoscopy for cellular observation of the gastrointestinal tract. Nat Clin Pract Gastroenterol Hepatol 2005; 2: 31-37

4 Kiesslich R, Goetz M, Burg J et al. Diagnosing Helicobacter pylori in vivo by confocal laser endoscopy. Gastroenterology 2005; 128 : 2119-2123

5 Guo YT, Li YQ Yu T et al. Diagnosis of gastric intestinal metaplasia with confocal laser endomicroscopy in vivo: a prospective study. Endoscopy 2008; 40: 547-553

\section{Bibliography}

DOI http://dx.doi.org/

10.1055/s-0032-1309706

Endoscopy 2012; 44: E263-E264

(c) Georg Thieme Verlag KG

Stuttgart · New York

ISSN 0013-726X

\section{Corresponding author}

G. Hundorfean, MD

University of Erlangen-Nuremberg

Ulmenweg 18

91054 Erlangen

Germany

Fax: +49-9131-8535102

gheorghe.hundorfean@uk-erlangen.de 